\title{
IMPLEMENTASI PENGENDALIAN INTERNAL PADA PENCEGAHAN DAN PENDETEKSIAN FRAUD RUMAH SAKIT DI BOJONEGORO
}

\author{
Isnaini Anniswati Rosyida \\ Universitas Islam Darul 'Ulum Lamongan \\ isnaini@unisda.ac.id
}

\begin{abstract}
This study aims to obtain an information related to the internal control of the prevention and detection of fraud at hospitals in Bojonegoro. Since hospitals are a very important health care network, services that should be more concerned with hospitals in the presence of medical services and medical equipment suppliers for all patients. Lack of service and medical devices is a mistake in internal control. The method in this research by analyzing the comparative approach that is descriptive analysis. Data collection with interviews and observations. Respondents in this study are employees who exist at these agencies. Detection of fraud, can not be separated from the knowledge of the triggers of cheating and fraudulent parties. What needs to be known to the party who gets the task to do the fraud detection, by knowing the trigger of the occurrence of fraud and which side will be more focused.
\end{abstract}

Keywords: Internal control, prevention and fraud detection

\begin{abstract}
Abstrak
Penelitian ini bertujuan untuk mendapatkan sebuah informasi yang berhubungan dengan pengendalian internal tentang pencegahan dan pendeteksian kecurangan pada rumah sakit di Bojonegoro. Karena rumah sakit merupakan suatu jaringan perawatan kesehatan yang sangat penting, maka layanan yang seharusnya lebih banyak diperhatikan pada rumah sakit dengan adanya pelayanan medis dan pemasok alat medis untuk semua pasien. Kurangnya pelayanan dan alat medis merupakan kesalahan pengendalian internal. Metode dalam penelitian ini dengan menganalisa pendekatan komparatif yaitu analisis desriptif. Pengumpulan data dengan wawancara dan pengamatan. Responden dalam penelitian ini adalah karyawan yang ada pada instansi tersebut. Pendeteksian terhadap kecurangan, tidak dapat dilepaskan dari pengetahuan tentang pemicu terjadinya kecurangan dan pihak mana yang melakukan kecurangan. Harus diketahui pihak yang melakukan pendeteksian kecurangan, dengan mengetahui pemicu terjadinya kecurangan dan pihak mana sehingga akan lebih terarah.
\end{abstract}

Kata kunci : Pengendalian internal, pencegahan dan pendeteksian fraud

\section{PENDAHULUAN}

Institusi perawatan kesehatan professional yang pelayanannya disediakan oleh dokter, perawat, serta tenaga ahli kesehatan lainnya merupakan sebuah rumah sakit yang merupakan industry yang padat karya dan padat modal. Berdasarkan definisinya padat 
karya ditandai dengan banyaknya tenaga kerja yang terlibat dalam aktivitas rumah sakit, padat modal yang berdasar dari aktiva rumah sakit berupa peralatan medis yang nilainya sangat material dan persediaan dan perputaran yang tinggi, sehingga perlu diperhatikan pada dua factor tersebut, karena proses pengadaan barang maupun jasa rumah sakit sering terjadi kecurangan mengakibatkan kerugian yang sangat besar, baik kuantitas, kualitas barang/jasa dan biaya yang dikeluarkan. Sebagian besar di perusahaan terjadi penyimpangan yang karena kecurangan pada proses pengadaan barang dan jasa yang menimbulkan kerugian cukup signifikan. Hal ini dapat menjadi obyek audit yang memerlukan pengujian lebih mendalam bagi seorang auditor tentang resiko (Purwitasari, 2013).

Proses pengadaan barang dan jasa, diperlukan upaya dan strategi untuk mencegah, mendeteksi dan mengungkap kecurangan terjadi pada pengadaan barang dan jasa. Pengelolaan rumah sakit yang baik adalah yang terkelola secara transparan, mandiri, akuntabel, bertanggungjawab dan wajar sehingga kinerja keuangan rumah sakit dapat dicapai sesuai dengan visi dan misinya. Belum adanya instrument organisasi yang memadai untuk menciptakan pengelolaan yang baik dan belum terbangunnya komitmen yang tinggi yang mengakibatkan munculnya penyimpangan, penyelewengan, penyelundupan dan korupsi. Sehingga fraud menjadi hal yang biasa di rumah sakit (Arfah, 2011).

Korupsi pengadaan barang CT Scan adalah fraud yang sering terjadi di rumah sakit seperti yang terjadi di Rumah Sakit Margono Soekarjo, Purwokerto, Banyumas dan korupsi pengadaan obat Dinas Kesehatan Baanyumas senilai merugikan uang Negarasejumlah Rp. 300 juta. RS.Kanujodso Djatiwibowo korupsi pengadaan alat alat kesehatan, diduga seorang pimpinan proyek terlibat korupsi kasus Magnetic Resonance Imaging (MRI) senilai Rp. 13,7 milyar (Hermiyetti, 2012)..

Diperlukan upaya yang lebih sistematis dalam menanggulangi korupsi menggunakan alur dalam memerangi korupsi yang lebih jelas. Penyebab utama terjadinya korupsi harus diidentifikasikan sehingga dapat dirumuskan strategi yang tepat menghilangkan atau mengurangi intensitas yang ditimbulkan dari penyebab tersebut. 
Strategi investigative untuk mendeteksi, menginvestigasi, serta menindaklanjuti hasil investigasi kasus Tindak pidana Korupsi, diperlukan pemahaman tentang pengendalian internal yang diterapkan oleh tenaga paramedis di rumahsakit, dan apabila diterapkan efektif maka dapat mencegah terjadinya fraud( kecurangan). Dibangun dan diimplementasikannya pengendalian internal diharapkan dapat menangkal penyelewengan yang dilakukan oleh para pelayanana public, khususnya pada bidang kesehatan seperti dokter dan tenaga paramedic lainnya.

\section{TINJAUAN PUSTAKA}

Fraud dalam jaminan kesehatan didefinisikan sebagai tindakan untuk mencurangi atau mendapat manfaat program layanan kesehatan dengan cara yang tidak sepantasnya, merupakan pengertian fraud secara khusus.

\section{Jenis Jenis Fraud Yang Terjadi Pada Kesehatan Atau Rumah Sakit}

1. Fraud / kecurangan pada pengadaan barang dan jasa.

Proses pengadaan barang maupun jasa di rumah sakit terjadi kecurangan yang mengakibatkan kerugian sangat besar, baik kuantitas, kualitas barang/jasa maupun biaya yang akan dikeluarkan.

2. Fraud/kecurangan pada tenaga kerja

Sering terjadi fraud/kecurangan pada

- Pelayanaan primer

- Pelayanan rujukan (RS)

- Lembaga keuangan menjamin asuransi

Sedangkan pihak pihak yang ada dalam Pencegahan dan Penindakan Fraud adalah :

- Pihak yang membayar (organisasi jaminan social, dan asuransi kesehatan)

Peserta asuransi memberi uang tunai langsung ke provider (dokter) agar bersedia memberkani pelayanan tertentu.

- Provider layanan kesehatan (rumah sakit, dokter, perawat, dan farmasi). 
Provider layanan kesehatan membeikan pengaruh yang kuat dalam membuat keputusan medis, dalam peresepan obat, menentukan lama waktu perawatan, merujuk pasien untuk perawatan lain atau pemeriksaan laboratorium.

- Pasien

Fraud yang dilakukan pasien dengan menyuap dokter mau memberi pelayanan lebih cepat, menggunakan kartu asuransi kesehatan milik orang lain, maupun memanipulasi penghasilan tidak perlu membayar biaya asuransi yang terlalu besar.

- Supplier (produsen peralatan medis atau perusahaan farmasi)

Menyuap provider agar menggunakan produknya dengan cara cara yang kurang pantas dari perusahaan farmasi, dengan memberi hadiah.

\section{Teori Fraud Triangel}

Berdasarkan teori dari Tuanakotta (2007) yang mengemukakan bahwa terdapat 3 pemicu utama yang dikenal dengan nama "fraud triangle" sehingga seseorang terdorong untuk melakukan fraud,(Purwitasari, 2013) yaitu :

a) Opportunity (kesempatan)

Manajemen dalam sebuah organisasi/perusahaan mempunyai kesempatan yang lebih besar melakukan fraud dibandingkan karyawannya. Kesempatan untuk melakukan fraud sangat berhubungan penerapan pengendalian internal dalam perusahaan apakah kuat atau lemah. Internal control yang lemah dikarenakan karena pengawasan, dan penyalahgunaan wewenang.

Dari 3 elemen fraud triangle, kesempatan merupakan elemen yang paling memungkinkan untuk diminimalisir melalui penerapan proses, prosedur, dan control serta cara mendeteksi awal terjadinya fraud.

Kesempatan dalam penelitian ini adalah :

- BPJS memiliki pengendalian intern lemah yang menyebabkan proses klaim asuransi dimanfaatkan oleh rumah sakit dengan melakukan fraud. 
- Pihak BPJS tidak mememiliki internal kontrol baik kontrol secara berkala maupun rutin terhadap pelaksanaan asuransi BPJS di lapangan.

- Rumah sakit diberikan saran oleh BPJS untuk menyediakan divisi anti fraud yang dapat membantu pihak BPJS mengontrol proses asuransi kesehatan BPJS, namun divisi anti fraud bekerja untuk rumah sakit bukan untuk BPJS.

- Adanya kemungkinan ada oknum yang bekerja sama dari kedua lembaga tersebut.

b) Pressure (tekanan)

Fraud karena tergantung kepada kondisi individu, tekanan keuangan, kebiasaan buruk dan kebiasaan lain yang merugikan.

Tekanan yang mungkin terjadi pada rumah sakit adalah :

- Tekanan dari shareholders maupun top eksekutif rumah sakit memperoleh laba yang tinggi sehingga terjadi fraud.

Fraud yang dilakukan oleh rumah sakit terjadi mungkin adanya oknum dari karyawan rumahsakit sehingga tekanan muncul dari pribadi karyawan bukan kesalahan dari rumah sakit seluruhnya.

c) Razionalization (rasionalisasi)

Apabila seseorang menganggap pembenaran atas fraud yang dilakukannya. Pelaku mencari alasan atau pembenaran bahwa fraud yang dilakukannya bukan tindakan bukan tindakan fraud. Seseorang mengetahui bahwa tindakan yang dilakukannya adalah salah dan termasuk tindakan criminal, tetapi mereka menganggap wajar tindakannya karena gaji yang mereka terima sangat tidak layak. Dan beranggapan masyarakat juga melakukan hal seperti itu.

Rumah sakit yang telah melakukan kecurangan dalam klaim BPJS mungkin memiliki :

- Pihak rumah sakit memungut uang kepada pasien BPJS karena uang pengganti dari BPJS kurang, sehingga pihak rumahsakit memungutnya untuk membayar kekurangan pasien.

- Manipulasi kelas perawatan ketika pasien datang mencari kelas perawatan yang sesuai dengan kelas premi BPJS penuh, namun pasien diterima pada kelas yang 
lebih rendah dan pihak rumah sakit berdalih klaim yang diajukan kepada pihak BPJS sesuai dengan kelas premi yang dibayarkan pasien BPJS tersebut sehingga pihak rumah sakit merasa tidak salah dengan apa yang dilakukan pihak rumah sakit .

\section{Timbul Fraud Di Lingkungan Rumah Sakit}

Menurut Sahriari (2010) menyatakan bahwa di lingkungan rumah sakit timbul fraud karena :

- Rendahnya gaji tenaga medis

- Sistem layanan kesehatan dan beban layanan kesehatan yang tidak seimbang

- Pemberian insentif yang tidak memadai dari penyedia layanan

- Pasokan peralatan medis yang kurang

- Sistem yang tidak efisien

- Pemberian fasilitas kesehatan yang tidak transparan

- Faktor budaya

\section{Bidang Fraud}

\section{Fraud yang terjadi pada pengadaan barang dan jasa}

Bentuk bentuk fraud yang sering dilakukan adalah kecurangan pada aktiva rumah sakit yang berupa peralatan medis dan persediaan obat. Dampak Fraud yang terjadi adalah adanya kekosongan peralatan medis dan obat obatan yang ada di rumah sakit, sedang pencegahan fraud nya dengan adanya Penerapan Sistem Pengendalian Internal.

\section{Fraud pada tenaga kerja}

Bentuk bentuk fraud yang dilakukan menurut workshop pedoman pencegahan fraud dalam jaminan kesehatan di rumah sakit (2014) adalah :

1. Upcoding

Artinya membuat kode penentuan jenis penyakit dan tindakan dari pelayanan yang lebih kompleks dari yang sebenarnya dikerjakan oleh institusi pelayanan kesehatan. 


\section{Cloning}

Artinya mengganti keadaan pasien dengan cara menyalin profil pasien lain dengan gejala yang sama seolah semua pasien dilakukan pemeriksaan lengkap dengan memakai sistem rekam medis elektronik dan membuat model spesifikasi profil pasien secara otomatis.

3. Phantom billing

Artinya Membuat tagihan yang tidak pernah mendapatkan pelayanan yang ditagihkaninstitusi rumah sakit .

4. Inflated Bills

Artinya menagihkan pelayanan rumah sakit yang lebih tinggi dari yang sebenarnya.

5. Service unbulding or fragmentation

Artinya Melakukan pelayanan yang tidak langsung secara keseluruhan tetapi dibuat beberapa kali pelayanan.

6. Self - referral

Artinya Memberikan pelayaanan kesehatan sendiri atau teman kerja dengan insentif uang atau komisi.

7. Repeat billing

Artinya penagihan obat-obatan dan alat kesehatan yang sama berualang ualang padahal hanya diberikan satu kali.

8. Length of stay

Artinya melakukan perpanjangan Masa rawat inap yang diperpanjang di institusi pelayanan kesehatan agar mendapat tariff yang lebih tinggi.

9. Type of room charge

Artinya biaya perawatan pasien ruangan yang ditagihkan pembayaran kelas perawatannya lebih tinggi daripada yang sebenarnya.

10. Time in OR

Artinya menagihkan prosedur menggunakan waktu rata-rata maksimal operasi, yang bukan durasi operasi yang sebenarnya.

11. Keystroke mistake 
Artinya dengan sengaja melakukan kesalahan dalam menginput penagihan pasien pada tarif untuk mendapat ganti tariff yang lebih tinggi.

12. Cancelled services

Artinya penagihan pada pembayaran padahal telah membatalkan pelayanan yang telah direncanakan.

13. No medical value

Artinya memberikan layanan kesehatan yang tidak bermanfaat dalam pemeriksaan dan penatalaksanaan pasien

14. Standard of care

Artinya tindakan yang berusaha memberikan pelayanan dengan menyesuaikan dari tariff yang ada, sehingga dikhawatirkan cenderung menurunkan kualitas dan standar pelayanan yang diberikan.

15. Unnecessary treatment

Artinya memberikan obat atau memberikan layanan kesehatan yang tidak dibutuhkan dan tidak diperlukan oleh pasien.

\section{Konsep Pencegahan Fraud Pengadaan Barang}

Tuanakotta (2007:159) mendefinisikan bahwa ada ungkapan yang mudah dalam menjelaskan penyebab atau akar permaslahan dari fraud. Ungkapan tersebut : fraud by need, by greed and by opportunity. Dapat diartikan bila ingin mencegah fraud, agar menekan sekecil mungkin penyebabnya. Organisasi yang diduga melakukan fraud secara internal tidak mau dipublikasikan, kasus tersebut ditutup dan masalahnya dianggap telah selesai.

Hall (2001), menyatakan fraud ditunjukkan pada penyajian fakta yang salah dilakukan oleh satu pihak ke pihak lain yang bertujuan untuk membohongi dan mempengaruhi pihak lain untuk bergantung pada fakta tersebut, fakta yang akan merugikannya dan berdasarkan pada peraturan yang berlaku.

Tujuan utama pencegahan fraud adalah menghapus sebab-sebab terjadinya fraud. Menurut Amrizal (2004:3) fraud sering terjadi karena : a) pengendalian internalyang lemah 
dan terjadi kelonggraan atau tidak efektif; b) pegawai bekerja namun tidak memikirkan kejujuran dan integritasnya; c) pegawai yang terlalu diatur, dimanfaatkan , disalahgunakan atau diperlakukan dengan tekanan yang besar agar mencapai sasaran dan tujuan keuangan; d) manajemen yang bekerja fraud, tidak efisien dan atau tidak efektif serta tidak mematuhi pada hokum dan peraturan yang berlaku; e)karyawan yang dipercaya mempynyai masalah pribadi,yaitu masalah keuangan, kesehatan keluarga, gaya hidup yang berlebihan; f) perusahaan memiliki sejarah atau tradisi terjadinya fraud (Arfah,2011).

Hermiyetti (2012) menyatakan bahwa melakukan pencegahan fraud adalah kegiatan yang dilaksanakan tentang penetapan kebijakan, system serta prosedur yang dapat membantu tindakan yang diperlukan oleh dewan komisaris, manajemen, dan personil lain dalam perusahaan yang dapat memberikan keyakinan memadai dalam mencapai tujuan organisasi yaitu: efektivitas dan efisiensi operasi, keandalan laporan keuangan, serta kepatuhan terhadap hokum dan peraturan yang berlaku (COSO 1992:13).

Menurut Tuanakotta (2007:162) pencegahan fraud dapat dilakukan dengan mengaktifkan pengendalian internal, yaitu pengendalian internal yang paling banyak diterapkan, yang menghalangi pencuri masuk ke halaman rumah orang.

\section{Dampak Korupsi Terhadap Sistem Manajemen Rumah Sakit}

Korupsi yang terjadi akan terjadi pada keadaan:

1. Organisasi rumah sakit merupakan lembaga yang mempunyai sisi bayangan yang semakin gelap;

2. Tidak relevannya ilmu manajemen yang diajarkan di pendidikan tinggi;

3. Terjadinya kolusif pada direktur yang diangkat (contohnya membayar untuk menjadi direktur) sehingga menjadi sulit menghargai ilmu manajemen;

4. Tidak seperti pada buku-teks tentang proses manajemen dan klinis di pelayanan.

\section{Penanganan Korupsi Pada Lingkup Kesehatan}

Pencegahan korupsi di sektor kesehatan dengan cara:

1. Tenaga kesehatan, pimpinan pemerintahan dan politik, serta konsultan, membangun karakter dimulai sejak masa kecil; 
2. Harus dilakukan secara baik, dan transparan tentang perekruitmen pimpinan lembaga kesehatan dan rumah sakit dan serta SDMnya;

3. Pendampingan kegiatan berpotensi korupsi sejak awal perencanaan, terutama pada proyek-proyek di sektor kesehatan yang rentan menjadi proyek yang dapat dirancang untuk dikorupsi;

4. Cermat dalam melakukan kegiatan, tentang Administrasi perkantoran;

5. Peraturan dan perundangan mengenai korupsi melalui pendidikan dan pelatihan harus dipahami dokter, tenaga kesehatan, manajer Rumah Sakit.

\section{Penelitian Terdahulu}

Fitriani (2017) melakukan penelitian tentang Pengaruh pengendalian internal komite audit terhadap pencegahan Fraud .Sedangkan Sanjayyana, dkk (2016) juga melakukan penelitian tentang Insurance Fraud Badan Penyelenggara Jaminan Sosial (BPJS) Kesehatan, serta Purwitasari(2013) meneliti tentang Pengaruh pengendalian internal dan komitmen organisasi dalam pencegahan Fraud Pengadaan barang yang mendapatkan hasil bahwa secara parsial variabel pada pengendalian internal dan komitmen organisasi berpengaruh secara signifikan terhadap variable pencegahan fraud pengadaan barang. Hermiyetti (2010) melakukan penelitian tentang pengaruh penerapan pengendalian internal terhadap pencegahan fraud pengadaan barang, Sri Hartatik (2016) melakukan penelitian tentang pencegahan kecurangan(fraud) dalam pelaksanaan program pada system jaminan social kesehatan (SJSN) di Rumah Sakit Umum.

\section{METODE PENELITIAN}

Penelitian ini menggunakan metode kualitatif dengan pendekatan deskriptif. Menurut Moeloeng (2007) definisi metode kualitatif adalah prosedur penelitian yang menghasilkan data deskriptif berupa kata tertulis atau lisan dari orang dan perilaku yang dapat diamati. Salah satu karakteristik dari penelitian kualitatif adalah deskriptif.

Teknik analisa data penulisan penelitian yang digunakan adalah deskriptif kualitatif. Digunakan metode deskriptif kualitatif dikarenakan bertujuan untuk memperoleh gambaran dari kondisi riil permasalahan serta bagaimana metode penerapan solusinya (Sula,2016). 


\section{HASIL DAN PEMBAHASAN}

\section{Bentuk Fraud Yang Dilakukan Oleh Rumah Sakit "X" Di Bojonegoro}

Beberapa kecurangan / fraud yang dilakukan pada Rumah Sakit "X" di Bojonegoro sangat beragam antara lain, fraud yang dilakukan oleh :

\section{Peserta Asuransi / Pasien}

Contoh:

- Fraud yang dilakukan Peserta / Pasien adalah pada hari pertama pasien berobat ke Rumah Sakit A dengan layanan BPJS, Pasien mendapatkan obat selama seminggu. Namun pada hari kedua pasien berobat ke Rumah Sakit B dengan layanan BPJS pula mendapatkan obat. Setelah mendapatkan obat tersebut, Pasien menjual obatobat yang telah diperolehnya kepada toko obat.

- Fraud dengan memberikan pernyataan yang tidak benar pada klaim.

\section{Pihak Asuransi}

- Fraud yang dilakukan Pihak Asuransi misalnya melakukan "Pending" artinya peserta asuransi mengajukan klaim tetapi dari pihak asuransi, pencairan klaim tersebut ditunda dengan alasan menunggu.

\section{Pihak pemberi Layanan kesehatan / Rumah sakit " $X$ " di Bojonegoro}

- Fraud yang sering dilakukan oleh pihak Rumah sakit ' $X$ ' di Bojonegoro antara lain : Up coding artinya berusaha membuat kode diagnose serta tindakan dari pelayanan yang lebih tinggi atau lebih kompleks dari sebenarnya yang dikerjakan. Contohnya :

a) kasus bedah, pasien direncanakan dan diindikasikan segera dilakukan operasi pengangkatan Appendicitis, tindakan yang dilakukan adalah Appendectomy, agar biaya klaim menjadi lebih tinggi. Maka dokter menambahkan operasi Lysis adhesi yang sebenarnya tidak ada perlengketan. Dan ini di tulis pada resume medis pasien yang sebenarnya/ fakta tidak dilakukan operasi.

b) Kasus pasien katarak, dilakukan rawat inap jika ada penyakit lain yang kronis (glukoma/peradangan mata). Kenyataannya pasien tersebut tidak mempunyai penyakit kronis lainnya dan seharusnya melakukan rawat jalan.Namun dokter 
menulis resum medisnya ada penyakit. Hal tersebut dilakukan karena dengan hanya rawat jalan, rumah sakit hanya memperoleh biaya yang lebih kecil (3.7 juta) dibanding dengan rawat inap (6 juta).

Canceled services artinya pembatalan pelayanan yang rencananya diberikan dan tetap ditagihkan pada system. Contoh fraud yang dilakukan misal ada seorang pasien yang akan operasi harus rawat inap 1 hari. Namun dengan alasan dokter tidak datang, maka pasien disuruh datang besok, pihak rumah sakit menagihkan biaya 1 hari (tentang penyakitnya saja). Setelah kedatangan pasien hari yang kedua pihak rumah sakit menagihkan dua kali (tentang penyakitnya dan tindakan/operasi).

No medical value artinya melakukan suatu layanan kesehatan yang tidak memberikan manfaat untuk pemerikasaan dan penatalaksanaan pasien.

Unnecessary treatment artinya melakukan suatu pengobatan atau pemberian layanan kesehatan yang tidak dibutuhkan dan tidak diperlukan oleh pasien.

Pencegahan dan pengurangan fraud di Rumah Sakit "X" di Bojonegoro dilakukan dengan cara :

- Mendorong pelaksanaan tata kelola organisasi dan tata kelola klinik yang baik.

- Meningkatkan kemampuan dokter dan petugas lain yang berkaitan dengan klaim;

- Menetapkan Regulasi Pencegahan, Pendeteksian dan Penindakan Fraud

1. Delegasi wewenang pengawasan fraud dari Kementerian Kesehatan kepada Dinas Kesehatan Provinsi dan Kabupaten

2. Kerjasama antara Dinas Kesehatan Provinsi dan Dinkes Kabupaten dengan tim independen untuk melakukan pengawasan

3. Pembentukan Unit Investigasi Khusus di setiap Kantor Regional BPJS

4. Memperkuat peran pengawas internal dan eksternal Rumah Sakit

A. Mengadakan Sosialisasi dan Pelatihan Upaya Pencegahan, Pendeteksian dan Penindakan Fraud 
- Kerjasama antara Kementerian Kesehatan dan perguruan tinggi untuk penyusunan materi dan pelatihan

B. Pembentukan Tim Anti Fraud di Rumah Sakit

1. Pelaksanaan program pencegahan berupa pendidikan anti fraud untuk staf rumah sakit

2. Pelaksanaan program deteksi dan investigasi internal untuk terjadinya fraud: monitoring dan evaluasi ketepatan klaim

3. Pelaksanaan program tindakan: pelaporan dan pengembalian dana

4. Pelaksanaan program penelitian: menggunakan data klaim RS untuk penelitian tentang fraud

Sedangkan upaya yang dilakukan oleh pihak Asuransi untuk menghindari adanya Fraud antara lain :

a. Setiap rumah sakit yang berkongsi dengan perusahaan asuransi diminta untuk membuat anti fraud, yang melihat apakah klaim diajukan oleh rumah sakit sesuai dengan ketentuan atau tidak.

b. Pihak asuransi membuat sebuah tim untuk mengendalikan mutu dan biaya yang terdiri dari unsur klinisi profesi (organisasi profesi) dan akademisi, yang memeriksa jumlah klaim yang diajukan oleh rumah sakit. Mengetahui jumlah klaim rumah sakit apakah wajar atau tidak.

c. Pemerintah telah menjalankan system Indonesian Case Base groups (InaCBG"s). Menggunakan system klaim yang diajukan rumah sakit yang wujudnya dalam satu paket. Pasien akan dirawat dalam satu hari atau lima hari, yang nominal klaimnya akan sama. Termasuk juga dengan jenis obat obatan yang dipakai, sudah disesuaikan dengan paket penyakitnya.

Menerapkan program anti fraud dan system mencegah praktik fraud, dibutuhkan peran Direktur Rumah Sakit yang meliputi usaha membangun system dalam mencegah fraud dimulai dengan memahami fraud, melalui edukasi dan sosialisasi, serta membuat 
kebijakan dan standar prosedur dalam pencegahan fraud serta membuat panduan tentang praktik clical pathway (alur yang menunjukkan tahap tahap pada pelayanaan kesehatan tentang hasil yang diharapkan), selanjutnya sosialisasi dan edukasi kembali, kebijakan dan prosedur anti fraud dengan segala buktinya, setelah itu monitor kepatuhan terhadap kebijakan dan standar prosedur anti fraud serta membangun system pengawasan internal.

\section{Pendeteksian Fraud Rumah Sakit Di Bojonegoro}

Pendeteksian terhadap kecurangan, tidak bisa dilepaskan dari pengetahuan mengenai hal-hal pemicu terjadinya kecurangan serta siapa atau pihakmana yang mungkin dapat melakukan kecurangan. Pihak yang mendapat tugas dalam melakukan pendeteksian kecurangan sangat diperlukan dan diketahui, karena dengan mengetahui factor pemicu terjadinya kecurangan serta siapa atau pihak mana yang melakukan lebih terarah.

Pemicu terjadinya kecurangan yang dilakukan seseorang ataupun sekelompok orang dirangkum dalam kata GONE (GONE THEORY yang merupakan singkatan dari Greed (keserakahan), Opportunity(Kesempatn), Need(Kebutuhan), dan Exposure(Pengungkapan). Dua factor yaitu Greed dan Need terutama berhubungan dengan individu (pelaku kecurangan) sedangkan Opportunity dan Exposure berhubungan dengan organisasi (korban perbuatan kecurangan).

\section{Fraud pada pengadaan barang dan jasa}

Pendeteksian dapat dilakukan dengan mencegah terjadinya kekosongan peralatan medis dan persediaan obat di bagian penyimpanan. Apabila dilakukan pemesanan peralatan medis dan obat dengan pemasok yang jarak tempuh perjalanannya melebihi satu hari, maka kebijakan yang dilakukan oleh Kepala Bagian Instalasi Farmasi adalah mencari pemasok cadangan agar tidak terjadi kekosongan atau kekurangan kebutuhan dalam rentang waktu tersebut. Selain itu, pengeluaran dan penggunaan obat dan peralatan medis menggunakan metode LIFO-FIFO untuk mencegah terjadinya penggunaan obat dan peralatan medis yang habis dan disesuaikan dengan kebutuhan pada saat itu.

\section{Fraud pada tenaga kerja}


Pendeteksian dapat dilakukan dengan

- Memahami gejala kecurangan

- Menggunakan pendekatan GONE theory (Greed,Opportunity,Need, dan Exposure) dan Fraud Triangel (Pressure,Opportunity,Rationalization)

- Mempertimbangkan factor psikologis dan factor individu Faktor seseorang yang melekat melakukan kecurangan. factor individu dapat dikategorikan menjadi dua :

- Berhubungan dengan keserakahan (greed)

- Motivasi yang ada berhubungan dengan kebutuhan (need)

- Memperoleh data gaya hidup dan kebiasaan pelaku fraud Pelaku yang telah melakukan fraud biasanya memiliki tingkah laku yang tidak seperti biasanya, dalam bertindak selalu merasa salah tingkah karena pelaku merasa ada yang mencurigainya bahwa dia telah melakukan kecurangan.

\section{SIMPULAN DAN SARAN}

Penelitian ini dapat ditarik kesimpulan bahwa dalam pencegahannya harus dilakukan pengendalian internal yang sangat berpengaruh terhadap pencegahan fraud dalam lingkungam rumah sakit. Dan apabila diterapkan dengan baik serta menekankan pada keefektifan pengendalian internal dan kekuatan pada lingkungan pengendalian, sehingga dapat mencegah kemungkinan terjadinya tindak kecurangan yang ada pada lingkungan rumah sakit. Bagaimana cara mengatasi fraud adalah tugas bersama dari suatu organisasi pemerintah dan system pengawasan internalnya. Pengenalan akan adanya kecurangan dan dampaknya menjadi hal yang sangat penting untuk diketahui oleh seluruh staf pegawai hingga manajemen puncak. Serta kesadaran untuk melakukan tindakan anti fraud dapat diawali dengan memberikan pengertian yang lebih tentang kerugian serta dampak fraud. Selanjutnya mengupayakan untuk menghilangkan penyebab fraud, kemudian melakukan tindakan hukuman serta penghargaan untuk mempercepat peningkatan kesadaran dan budaya kerja tanpa fraud. Sedang dalam pendeteksian kecurangan, tidak bisa jauh dari pengetahuan hal-hal yang menjadi pemicu terjadinya kecurangan serta siapa atau 
pihakmana yang melakukan kecurangan, karena dengan mengetahui factor pemicu terjadinya dan siapa atau pihak mana yang melakukan akan diketahui lebih terarah.

\section{DAFTAR PUSTAKA}

Fitriani, 2017. Pengaruh Pengendalian Internal dan Komite Audit terhadap pencegahan Fraud, Fakultas Ekonomika dan Bisnis Universitas Diponegoro Semarang

Hall, J.A (2001) Sistem Informasi Akuntansi, Jakarta. Salemba Empat

Hartatik, 2016, Pencegahan Kecurangan (Fraud) dalam pelaksanaan Program Jaminan Kesehatan pada system jaminan social kesehatan (SJSN) di Rumah Sakit Umum Daerah Menggala Tulang Bawang, Vol 10 Issue 4

Hermiyetti, 2010. Penerapan Pengendalian Internal Terhadap Pencegahan Kecurangan Pengadaan Barang “Jurnal Akuntansi dan auditing Indonesia Vol 14 No. 2, 2010 “ Jakarta: STEKPI

Purwitasari, 2013. Pengaruh Pengendalian Internal dan Komitmen Organisasi dalam Pencegahan Fraud Pengadaan Barang, Fakultas Ekonomika Universitas Widyatama Bandung

Ringkasan Hasil Seminar, 22 Mei 2013 Korupsi di sector Kesehatan dan Pencegahannya, Yogyakarta

Sanjayyana, dkk, 2016. Insurance Fraud Badan Penyelenggara Jaminan Sosial (BPJS) Kesehatan, Fakultas Ekonomi Universitas Islam Indonesia

Tuanakotta, T, M. 2007 Akuntansi Forensik dan Audit Investigatif, Jakarta; Lembaga Penerbit Fakultas Ekonomi Universitas Indonesia (LPFE UI)

Workshop Pedoman Draft - Pencegahan-Fraud di Rumah Sakit 